\title{
Study of thyroid dysfunction in pregnancy
}

\author{
Dr.M.Banupriya Ms, Dgo ${ }_{\text {assistant Professor, }}{ }^{1}$ Dr.E.Princey Rajakumari Md, $\mathrm{Og}^{2}$ \\ 2 assistant Professor, \\ Department Of Obstetrics And Gynecology, Coimbatore Medical College, Coimbatore.
}

\begin{abstract}
Abtract: This study was conducted to analyze the incidence, antenatal \& postnatal complications, perinatal outcome and to be advocate routine screening for thyroid disorders in pregnancy in year oct 2015 to sep 2016 at CMCH Coimbatore. This study was prospective, interventional and observational study with 50 cases which was already diagnosed or diagnosed when suspected as pregnancy with thyroid disorders.Total number of patients who were admitted in labour room with pregnancy -12873, out of these 4\% aborted in the form of complete and incomplete abortion, missed abortion. $2.09 \%$ patient delivered before the completion of 37 weeks [preterm] and $0.932 \%$ patient were diagnosed as the pregnancy with intrauterine fetal demise and delivered vaginally. The commonest thyroid disorder found in pregnancy is hypothyroidism and it adversely affects the maternal and fetal health in the form of neonatal and maternal mortality and morbidity.If thyroid disorders are detected and treated either before or in early pregnancy, the adverse maternal-fetal outcome can be prevented. Hence we recommend that thyroid screening should be made universal for all antenatal patients.
\end{abstract}

Keywords: Pregnancy, hyperthyroidism, hypothyroidism .

\section{Introduction}

Thyroid function is very intimately related to the reproductive performance in women.Both hyperthyroidism and hypothyroidism lead to menstrural irregularities; severe hypothyroidism commonly associated with ovulation failure and infertility. Ovulation and conception can occur with mild hypothyroidism ,although the risk of abortion,stillbirth and prematurity are increased.

Pregnancy is associated with major changes in the physiology of the pituitary-thyroid axis and iodine metabolism. Thyroid gland increases by $10 \%$ in size during pregnancy in iodine replete areas and $20-40 \%$ in areas of iodine deficiency. Pregnancy has a goitrogenic effect on the thyroid because of the increased demand of thyroid hormones to maintain the increased maternal hormone levels and meet the requirements of the fetus.

Thyroid disease is the second most common cause of endocrine dysfunction in the women of child bearing age after diabetes. Thyroid disorder is a disorder that results when the thyroid gland produces more or less thyroid hormone than the body needs. Excess thyroid hormone is called hyperthyroidism and can cause many of the bodys functions to speed up. Too little thyroid hormone is called hypothyroidism, in which many of the bodys functions slow down . Subclinical hypothyroidism occur when thyrotropin[TSH] levels are elevated but thyroxine [T4] and triiodothyroxine [T3] levels are normal.

Overt hypothyroidism in the mother is associated with significantly increased risk of miscarriages, anaemia in pregnancy, pre-eclampsia,abruption placenta and postpartum haemorrhage, premature baby, low birth weight and increased neonatal respiratory distress and more admissions to the neonatal intensive care unit.

\section{Materials And Methods}

This study was conducted at Govt. Coimbatore Medical College Hospital ,Coimbatore . This study found 50 patients who were admitted in our hospital from oct 2015 to sep 2016 as pregnancy with thyroid disorder either already diagnosed or diagnosed when suspected. Patients were observed for obstetric and clinical history , investigations, antepartum complications, mode of delivery ,postpartum complications, perinatal outcome and treatment.

\section{Results And Analysis}

Total number of patients who were admitted in labour room with pregnancy was 12873 , out of these $4 \%$ aborted in the form of complete and incomplete abortion, missed abortion, patient delivered before the completion of 37 weeks [preterm] was $2.09 \%$ and patient were diagnosed as the pregnancy with intrauterine fetal demise - 
$0.932 \%$ and delivered vaginally. These entire figure show that $7.022 \%$ patient went to home without a successful outcome of pregnancy .

Thyroid disorders are among the common endocrine problems in pregnant women. It is now well established that not only overt ,but subclinical thyroid dysfunction also has adverse effects on maternal and fetal outcome. There are few data from India about the prevalence of thyroid dysfunction in pregnancy. With this back ground, this study aims to find prevalence of thyroid dysfunction in pregnancy and its impact on obstetric outcome and need for universal screening of pregnant women for thyroid diseases.

This study was conducted at Govt.Coimbatore Medical College Hospital ,Coimbatore . Number of patients having pregnancy with thyroid disease from oct 2015 to sep 2016 was 50 [0.388\%] of total admission.In our study no of patients with hypothyroidism were very high -45 [0.349\%] as compared to those with hyperthyroidism$4[0.031 \%]$. A single case of subclinical hypothyroidism [0.007\%] was also diagnosed during our study .Similar results were found in study of Abalovich et al.[2007], they suggested that thyroid disorders are the second most common endocrinological disorder found in pregnancy next to diabetes. They found that overt hypothyroidism is estimated to occur in $0.3-0.5 \%$ of pregnancies. Subclinical hypothyroidism appears to occur in 2-3 \%, and hyperthyroidism was found in $0.4 \%$.

In our study hypothyroidism was found in $0.349 \%$ hyperthyroidism was $0.031 \%$ and subclinical hypothyroidism was $0.007 \%$ of total no of pregnant patients admitted in CMCH ,Coimbatore. Similar results were found in study of Klein et al.[1991] they found that hypothyroidism is common in pregnancy with an estimated prevalence of $\quad 2-3 \%$ and $0.3-0.5 \%$ for subclinical and overt hypothyroidism respectively .

In our study the number of patients with subclinical hypothyroidism and hyperthyroidism are less as compared to those found in literature. This difference could be explained by the lack of awareness,attendance in antenatal clinic and routine antenatal screening for thyroid dysfunction and also because this study included those patients who were already diagnosed with thyroid disorders.

In our study the prevalence of thyroid disorders was more common in the younger [20-25 year] that was $52 \%$ and primi gravid was $56 \%$.In consistence to our study similar results were also found in study done by patowary et al. during 1998. According to them the prevalence of goiter in kamalpur district of Gauhati among 3990 population, was $37.3 \%$ in the age group of $13-18$ yerars.

Our study suggested that prevalence of previous pregnancy loss is more common in patients of pregnancy with thyroid disorder.

The prevalence of hypothyroidism in our study was highest [ $0.349 \%$ ] as compared to other thyroid disorder. In this study the overall incidence of thyroid disorder was low [0.388\%]as compared to other studies. Klein et al [1991] - found that hypothyroidism is common in pregnancy with estimated prevalence of 2-3 \%.This difference is due to lack of routine antenatal screening for thyroid disorders and study was done only on already diagnosed patients.

The incidence of cesarean section was low $16 \%$ as compared to vaginal delivery $64 \%$ in this study .The indication for cesarean section was pregnancy with BOH, GHT with IUGR was 25\%,37.50\%,12.50\% respectively .The majority of cesarean sections were done for pregnancy with BOH and GHT.This indicates that thyroid disorders directly influences the maternal and fetal health. Hence our study shows that thyroid disorders are associated with pregnancy loss, GHT and IUGR.All these complication adversely affects the perinatal outcome.

The prevalence of anemia in our study was $60 \%$.Anemia is leading risk factor that is directly associated with maternal morbidity and mortality.In consistence to our study similar result were found in study of Fein and Rivlin [1975] they suggested that nutritional deficiencies are known to develop in subclinical hypothyroidism , the most recognized one is iron deficiency.The resulting anemia can be in the form of normochromic, normocystic, hypochromic ,microcystic,macrocystic or megaloblastic anemia. Anemia is estimated to affect up to $60 \%$ of patients with hypothyroidism and is not related to severity or duration of thyroid insufficiency .

In our study $78 \%$ of patients with thyroid disorder delivered at term , 18\% patients delivered preterm and 4 $\%$ aborted before age of viability.

An article in the Journal of Clinical Endocrinology and Metabolism, August 1997 states ,the risk of miscarriage is twice as high in women who have antithyroid antibodies than in those who do not ... and Journal of Obstetrics and Gynecology 1997 states the risk of miscarriage is higher when a women is positive for antithyroid microsomal antibodies.Roberto Negro et al.[2005]- found that euthyroid pregnant women who are positive for TPOAb develop impaired thyroid function, which is associated with an increased risk of miscarriage and premature deliveries.Substitutive treatment with levothyroxine is able to lower the chance of miscarriage and premature delivery . 
Study Of Thyroid Dysfunction In Pregnancy

\begin{tabular}{|l|l|l|}
\hline $\begin{array}{l}\text { Total no of patient admitted in labour } \\
\text { room }\end{array}$ & 12873 & $\%$ \\
\hline Full term & 7499 & $58.25 \%$ \\
\hline Preterm & 270 & $2.09 \%$ \\
\hline IUD & 120 & $0.932 \%$ \\
\hline LSCS & 4119 & $31.99 \%$ \\
\hline $\begin{array}{l}\text { MVA for incomplete \&complete abortion } \\
\text {,missed abortion }\end{array}$ & 516 & $4 \%$ \\
\hline Total patients of thyroid disorders & 50 & $0.388 \%$ \\
\hline Hypothyroidism & 45 & $0.349 \%$ \\
\hline Hyperyhyroidism & 4 & $0.031 \%$ \\
\hline Subclinical hypothyroidism & 1 & $0.007 \%$ \\
\hline
\end{tabular}

Distribution According To Age

\begin{tabular}{|l|l|l|}
\hline AGE & NUMBER & $\%$ \\
\hline $20-25$ year & 26 & $52 \%$ \\
\hline $26-30$ year & 18 & $36 \%$ \\
\hline $31-35$ year & 4 & $8 \%$ \\
\hline$>35$ year & 2 & $4 \%$ \\
\hline
\end{tabular}

Distribution According To Gravid

\begin{tabular}{|l|l|l|}
\hline Gravida & Number & $\%$ \\
\hline Primi Gravid & 28 & $56 \%$ \\
\hline Second Gravid & 14 & $28 \%$ \\
\hline Third Gravid & 5 & $10 \%$ \\
\hline Four Gravid Or > & 3 & $6 \%$ \\
\hline
\end{tabular}

Distribution According To Thyroid Disorder

\begin{tabular}{|l|l|l|}
\hline TYPE OF DISORDER & NUMBER & $\%$ \\
\hline Hypothyroiod & 45 & $90 \%$ \\
\hline Hyperthyroid & 4 & $8 \%$ \\
\hline Subclinical hypothyroid & 1 & $2 \%$ \\
\hline
\end{tabular}

Distribution According Indication Of Caesarean Section

\begin{tabular}{|l|l|l|}
\hline INDICATION & NUMBER & $\%$ \\
\hline Pregnancy with BOH & 2 & $25 \%$ \\
\hline $\begin{array}{l}\text { GHT ,preeclampsia ,eclampsia with caesarian } \\
\text { section }\end{array}$ & 3 & $37.50 \%$ \\
\hline GHT ,preeclampsia with IUGR & 1 & $12.50 \%$ \\
\hline Nonprogress of labour & 1 & $12.50 \%$ \\
\hline Foetal distress & 1 & $12.50 \%$ \\
\hline
\end{tabular}

Distribution According To Mode Of Delivery

\begin{tabular}{|l|l|l|}
\hline Mode Of Delivery & Number & $\%$ \\
\hline Full Term Vaginal Delivery & 32 & $64 \%$ \\
\hline Preterm Vaginal Delivery & 8 & $16 \%$ \\
\hline Iufd Vaginal Delivery & 1 & $2 \%$ \\
\hline Total Lscs & 8 & $16 \%$ \\
\hline Full Term Lscs & 6 & $12 \%$ \\
\hline Preterm Lscs & 2 & $4 \%$ \\
\hline Abortion & 2 & $4 \%$ \\
\hline
\end{tabular}

Distribution According To Hb Concentration

\begin{tabular}{|c|c|c|c|c|}
\hline $\mathrm{Hb}$ Concentration & $\begin{array}{l}\text { Numb } \\
\text { Hypo }\end{array}$ & Hyper & \%Нуро & Hyper \\
\hline$>11 \mathrm{gms}$ & 18 & 2 & $39.13 \%$ & $50 \%$ \\
\hline 7-10.9 Gms & 25 & 2 & $54.34 \%$ & $50 \%$ \\
\hline $4-6.9 \mathrm{gms}$ & 3 & 0 & $6.52 \%$ & $0 \%$ \\
\hline$<4 \mathrm{gms}$ & 0 & 0 & $0 \%$ & $0 \%$ \\
\hline
\end{tabular}


Distribution According To Pregnancy Outcome

\begin{tabular}{|l|l|l|}
\hline GESTATIONAL AGE & NUMBER & $\%$ \\
\hline Term & 39 & $78.0 \%$ \\
\hline Preterm $[<37 \mathrm{wks}]$ & 9 & $18.0 \%$ \\
\hline Abortion $[<20 \mathrm{wks}]$ & 2 & $4.0 \%$ \\
\hline
\end{tabular}

Distribution According To Foetal Outcome

\begin{tabular}{|l|l|l|}
\hline Total live birth & 47 & $\%$ \\
\hline Live healthy baby & 26 & $55.31 \%$ \\
\hline IUGR baby & 6 & $12.76 \%$ \\
\hline Low birth baby & 12 & $25.53 \%$ \\
\hline Intrauterine fetal demise & 1 & $2.12 \%$ \\
\hline Abortion & 2 & $4.0 \%$ \\
\hline Neonatal morbidity & 12 & $25.53 \%$ \\
\hline Neonatal mortality & 3 & $6.38 \%$ \\
\hline
\end{tabular}

Distribution According To Blood Pressure And Thyroid Disorder

\begin{tabular}{|l|l|l|l|l|}
\hline $\begin{array}{l}\text { Blood Pressure } \\
\text { [Systolic/Diastolic] }\end{array}$ & Hypothyroidism & Hyperthyroidism & $\begin{array}{l}\text { Hypothyroidism } \\
\text { Percentage }\end{array}$ & $\begin{array}{l}\text { Hyperthyroidism } \\
\text { Percentage }\end{array}$ \\
\hline $110-130 / 90 \mathrm{Mmhg}$ & 34 & 2 & $73.91 \%$ & $50 \%$ \\
\hline $130-150 />90 \mathrm{mmhg}$ & 8 & 1 & $17.39 \%$ & $25 \%$ \\
\hline$>150 / 110 \mathrm{Mmhg}$ & 4 & 1 & $8.69 \%$ & $25 \%$ \\
\hline
\end{tabular}

Distribution According To Previous History Of Infertility And Diabetes

\begin{tabular}{|l|l|l|l|}
\hline Type of disorder & Infertility & Diabetes & Others \\
\hline Hypothyroidism & 13 & 2 & 1 RHD \\
\hline Hyperthyroidism & 1 & 0 & \\
\hline
\end{tabular}

Distribution According To Antepartum \& Postpartum Complication

\begin{tabular}{|l|l|l|}
\hline Complication & Number & $\%$ \\
\hline Aph & 1 & $2.0 \%$ \\
\hline Pph & 1 & $2.0 \%$ \\
\hline Iugr & 6 & $12.0 \%$ \\
\hline Oligohydrominas & 1 & $2.0 \%$ \\
\hline Poly Hydrominas & 1 & $2.0 \%$ \\
\hline Ght And Preeclampsia & 12 & $24.0 \%$ \\
\hline Neonatal Mortality & 3 & $6.38 \%$ \\
\hline Maternal Mortality & 0 & $0 \%$ \\
\hline Anemia & 26 & $52.0 \%$ \\
\hline
\end{tabular}

Our study also suggest that there was significant prevalence of IUGR, low birth weight ,neonatal morbidity,mortality in patients with thyroid disorder [12.76\%,25.53\%,25.53\%,6.38\%].Our study shows that there was increased association of GHT and anemia in patients with thyroid disease. These two complications are the major risk factor for development of IUGR ,low birth weight babies and prematurity in affected patients. In our study $45 \%$ of total patients of pregnancy with thyroid disorder were hypertensive , of these $25 \%$ had severe hypertension.Maternal and perinatal morbidity increases in women with gestational hypertension .In study of Gofton et al.[2001] induction of labor and cesarean section in women with GHT were almost double as those in the normotensive.

In our study common complications occurring in patients with thyroid disorders were anemia-60\% GHT45\% IUGR-25.53\% LBW-25.53\% neonatal morbidity and mortality was $25.53 \%$ and $6.38 \%$. There was no case of maternal mortality in the study group. All these complication made pregnancy a high risk in those who had thyroid disorder.45\% of the patients in our study had a hospital stay of seven or more days, suggested increased maternal morbidity.The present study also suggests that there is more prevalence of infertility in hypothyroid patients.

\section{References}

[1]. Okosieme, OE; Marx,H; Lazarus,JH (Sep 2008). "Medical management of thyroid dysfunction in pregnancy and the postpartum.". Expert opinion on pharmacotherapy. 9 (13): 2281-93. doi:10.1517/14656566.9.13.2281. PMID 18710353.

[2]. Jump up to: ${ }^{\mathrm{b} c}$ Spencer, L; Bubner, T; Bain, E; Middleton, P (21 September 2015). "Screening and subsequent management for thyroid dysfunction pre-pregnancy and during pregnancy for improving maternal and infant health.". The Cochrane database of systematic reviews. 9: CD011263. doi:10.1002/14651858.CD011263.pub2. PMID 26387772. 
[3]. Jump up to: ${ }^{\text {b c }}$ Korevaar, Tim I M; Muetzel, Ryan; Medici, Marco; Chaker, Layal; Jaddoe, Vincent W V; de Rijke, Yolanda B; Steegers, Eric A P; Visser, Theo J; White, Tonya; Tiemeier, Henning; Peeters, Robin P (September 2015). "Association of maternal thyroid function during early pregnancy with offspring IQ and brain morphology in childhood: a population-based prospective cohort study". The Lancet Diabetes \& Endocrinology. 4: 35-43.doi:10.1016/s2213-8587(15)00327-7.

[4]. Jump up^ Smyth, PP; Hetherton, AM; Smith, DF; Radcliff, M; O'Herlihy, C (Sep 1997). "Maternal iodine status and thyroid volume during pregnancy: correlation with neonatal iodine intake.". The Journal of Clinical Endocrinology and Metabolism. 82 (9): 2840doi:10.1210/jcem.82.9.4203. PMID 9284707.

[5]. Jump up^ WHO S, Andersson M, de Benoist B, Delange F, Zupan J (Dec 2007). "Prevention and control of iodine deficiency in pregnant and lactating women and in children less than 2-years-old: conclusions and recommendations of the Technical Consultation." (PDF).Public health nutrition. 10 (12A): 1606-11. doi:10.1017/S1368980007361004.PMID 18053287.

[6]. Jump up^ Klein, RZ; Haddow, JE; Faix, JD; Brown, RS; Hermos, RJ; Pulkkinen, A; Mitchell, ML (Jul 1991). "Prevalence of thyroid deficiency in pregnant women.". Clinical endocrinology. 35(1): 41-6. doi:10.1111/j.1365-2265.1991.tb03494.x. PMID 1889138.

[7]. Jump up ${ }^{\wedge}$ Mandel SJ. "Hypothyroidism and chronic autoimmune thyroiditis in the pregnant state: maternal aspects." Best Pract Res Clin Endocrinol Metab. 2004 ; 18: 213-24.

[8]. Jump up^ Mandel, SJ (Jun 2004). "Hypothyroidism and chronic autoimmune thyroiditis in the pregnant state: maternal aspects.". Best practice \& research. Clinical endocrinology \& metabolism. 18 (2): 213-24. doi:10.1016/j.beem.2004.03.006. PMID 15157837.

[9]. Jump up^ Glinoer, D; Soto, MF; Bourdoux, P; Lejeune, B; Delange, F; Lemone, M; Kinthaert, J; Robijn, C; Grun, JP; de Nayer, P (Aug 1991). "Pregnancy in patients with mild thyroid abnormalities: maternal and neonatal repercussions.". The Journal of Clinical Endocrinology and Metabolism. 73 (2): 421-7. doi:10.1210/jcem-73-2-421.PMID 1906897.

[10]. Jump up^ Davis, LE; Leveno, KJ; Cunningham, FG (Jul 1988). "Hypothyroidism complicating pregnancy.". Obstetrics and gynecology. 72 (1): 108-12. PMID 3380497. 